\title{
Long-period ground motions in a laterally inhomogeneous large sedimentary basin: observations and model simulations of long-period surface waves in the northern Kanto Basin, Japan
}

\author{
Shunsuke Takemura ${ }^{1 *}$, Mai Akatsu', Kei Masuda², Kengo Kajikawa² and Kazuo Yoshimoto ${ }^{1}$
}

\begin{abstract}
To conduct practical evaluations of the long-period ground motions (period of 4 to $8 \mathrm{~s}$ ) in a laterally inhomogeneous large sedimentary basin, we constructed a three-dimensional (3D) sedimentary velocity structure model for the northern Kanto Basin in Japan using a simple velocity gradient function, where strong lateral variations of seismic velocities in the sediments were expected. The model construction employs waveform analysis and geophysical data from vertical seismic profiling and microtremor surveys in the target region. To validate the velocity structure model, we conducted large-scale 3D finite-difference method simulations of the long-period ground motions for two shallow moderate earthquakes: the northern Tochigi earthquake and the northern Ibaraki earthquake. The simulation results for both earthquakes accurately reproduced the observed long-period ground motions in terms of arrival times, amplitudes, and durations of surface waves. By detailed comparisons of the seismograms for observational and simulated data, we demonstrated that the lateral variation of the seismic velocities in the sediments determines the characteristics of the surface wave propagation in the northern Kanto Basin. Such analyses can provide a better understanding of the complex propagation characteristics of surface waves in laterally inhomogeneous, large sedimentary basins.
\end{abstract}

Keywords: Long-period ground motion; Surface wave propagation; Sedimentary S-wave velocity; Kanto Basin

\section{Background}

Long-period ground motions with dominant periods of several to $10 \mathrm{~s}$ are observed frequently during shallow local and/or regional earthquakes, especially in large sedimentary basins (e.g., Beck and Hall 1986; Shin and Teng 2001; Koketsu et al. 2005). Long-period ground motion has the potential to cause significant resonance in basins, and this can lead to severe damage of largescale, man-made structures such as high-rise buildings, oil storage tanks, and suspension bridges (e.g., Koketsu and Miyake 2008). Therefore, to assist disaster mitigation efforts for future large earthquakes, it is necessary to evaluate the characteristics of long-period ground

\footnotetext{
* Correspondence: shunsuke@yokohama-cu.ac.jp

'Department of Material System Science, Graduate School of Nanobioscience, Yokohama City University, 22-2, Seto, Kanazawa-ku, Yokohama 236-0027, Japan

Full list of author information is available at the end of the article
}

motions in relation to the three-dimensional (3D) heterogeneous structure of large sedimentary basins.

In the Kanto Basin (see Figure 1), where the biggest metropolitan area of Japan is located, many studies on long-period ground motions have been conducted from both the scientific and engineering point of views (e.g., Yamanaka et al. 1989; Kinoshita et al. 1992; Yamazaki et al. 1992; Miyake and Koketsu 2005; Furumura and Hayakawa 2007). The dominant period of the long-period ground motions observed in the Kanto Basin tends to be approximately $7 \mathrm{~s}$ for shallow moderate-to-large earthquakes (e.g., Miyake and Koketsu 2005; Furumura and Hayakawa 2007; Furumura et al. 2011), which is strongly controlled by the velocity structure at depths of less than $2 \mathrm{~km}$ (e.g., Yoshimoto and Takemura 2014b). Using seismic data from dense strong motion networks in the Kanto Basin (Kinoshita 1998; Okada et al. 2004), previous studies have revealed that the long-period ground motions are 


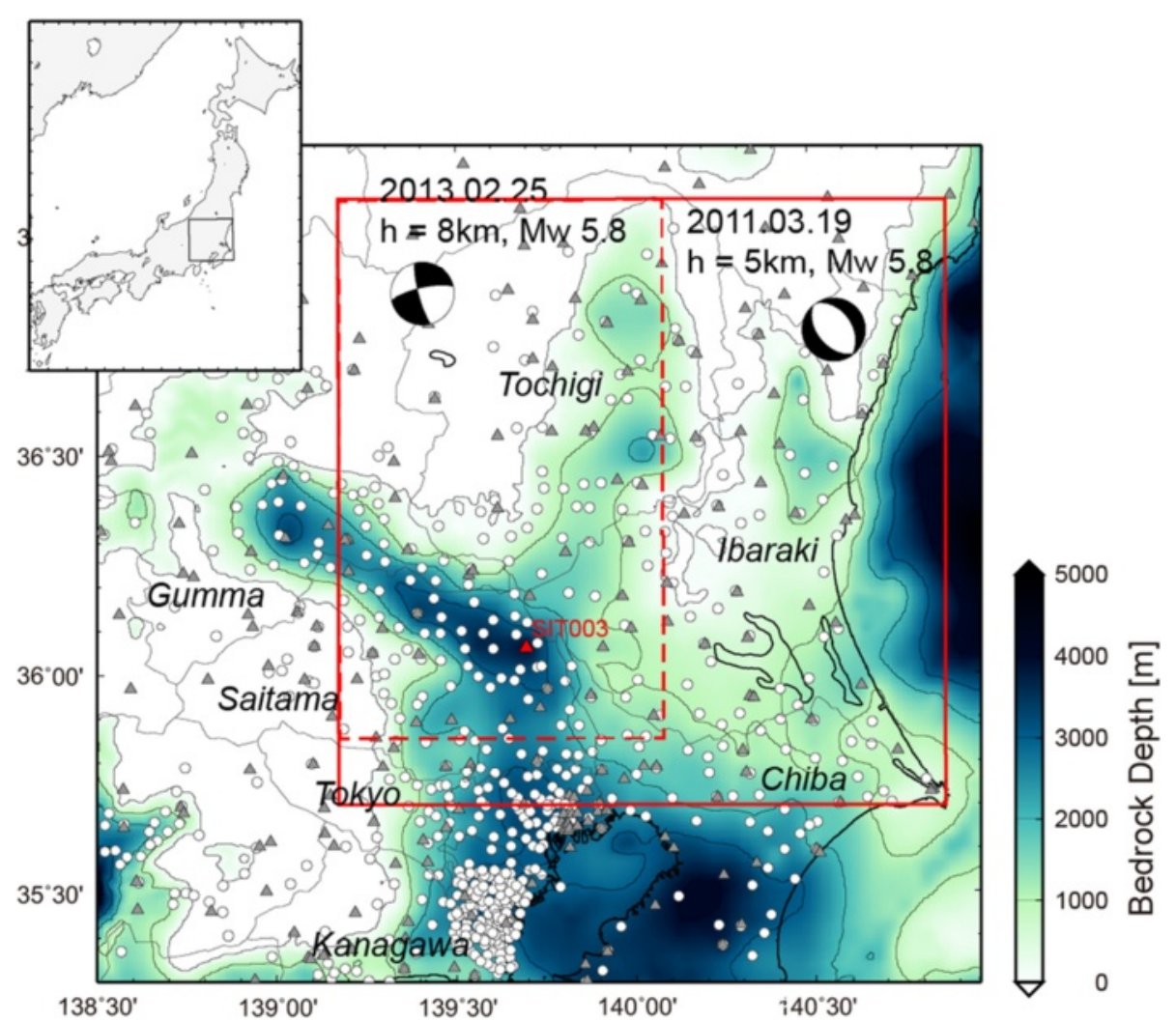

Figure 1 Spatial distributions of JIVSM bedrock depth and strong motion stations in the Kanto region, Japan. Gray triangles and white circles are K-NET/KiK-net (Kinoshita 1998; Okada et al. 2004) and SK-net stations, respectively. Dashed and solid red rectangles show the simulation areas of 3D waveform modeling and validation of the constructed velocity structure model, respectively. Plotted focal mechanisms were used in 3D FDM simulations.

generated by surface waves propagating over the thick sediments in the Kanto Basin (e.g., Koketsu and Kikuchi 2000; Miura and Midorikawa 2001; Furumura and Hayakawa 2007; Hayakawa 2009). The nature of the surface wave propagation reported by these studies is very complex, and current data imply that there is strong lateral inhomogeneity in the sedimentary structure of the Kanto Basin.

Extensive efforts to construct a 3D structure model of the Kanto Basin have been put forth by many researchers (e.g., Yamanaka and Yamada 2006; Koketsu et al. 2008, 2009; Fujiwara et al. 2009). Using available geophysical and geological information in Japan, Koketsu et al. $(2008,2009)$ proposed the Japan Integrated Velocity Structure Model (JIVSM), which is one of the latest and most widely used structure models for the evaluation of strong and long-period ground motions of large earthquakes (e.g., Iwaki et al. 2013; Maeda et al. 2013b), the estimation of rupture complexities for large earthquakes (e.g., Koketsu et al. 2011; Asano and Iwata 2012), and the simulation of seismic wave scattering (e.g., Maeda et al. 2014; Takemura and Yoshimoto 2014). The JIVSM represents the 3D heterogeneous subsurface structure using 23 constant-velocity layers including those of the crust, the mantle, the Philippine Sea (PHS) Plate, and the Pacific (PAC) Plate, and also the complex basement shapes of sedimentary basins. Despite such a detailed model of the subsurface structure, precise evaluations of the long-period ground motions for the Kanto Basin still have room for improvement, compared to the similar trials for other large sedimentary basins in Japan, e.g., the Osaka Basin (e.g., Iwaki and Iwata 2010) and the Nobi Basin (e.g., Horikawa et al. 2008).

Recently, Yoshimoto and Takemura (2014a) suggested that realistic modeling of the sedimentary velocity structure is necessary for the precise evaluation of longperiod ground motions in the northern Kanto Basin. Using a simple velocity gradient function (Ravve and Koren 2006), they proposed the construction of a smooth-varying 3D velocity structure model of the sediments from the vertical seismic profile (VSP) measurements of 14 deep boreholes in the Kanto Basin. Although their 3D finite-difference method (FDM) simulations successfully reproduced the excitation and propagation of long-period surface waves in a limited 
area of the northern edge of the Kanto Basin, the Kanto Basin is too large to achieve a detailed modeling of the $3 \mathrm{D}$ velocity structure using data from only 14 boreholes.

In this study, we construct a new $3 \mathrm{D}$ velocity structure model for the northern Kanto Basin (area outlined by the red square in Figure 1), which can be used for the precise evaluation of long-period ground motions with periods of 4 to $8 \mathrm{~s}$. The model construction employs waveform analysis and available geophysical data in this region. The model constructed in this study exhibits strong lateral variations of $S$-wave velocities in the northern Kanto Basin, which may have large effects on the long-period surface wave excitation and propagation. In order to validate this model, we conducted large-scale 3D FDM simulations of the long-period ground motion for two shallow moderate earthquakes in northern Tochigi and northern Ibaraki and confirmed that there was good agreement between our simulation results and the observed seismograms. Based on the simulation results, we discuss the characteristics of surface wave propagation in the laterally inhomogeneous sedimentary basin.

\section{Methods}

Depth-varying properties of sedimentary S-wave velocity Yoshimoto and Takemura (2014a) pointed out that the depth-varying properties of $S$-wave velocity in the Kanto Basin can be practically characterized by a simple velocity gradient function (Ravve and Koren 2006). The depth-dependent $S$-wave velocity function is represented by the following equation:

$$
V_{\mathrm{S}}(z)=V_{0}+\Delta V\left[1-\exp \left(-\frac{\alpha z}{\Delta V}\right)\right]
$$

where $V_{0}$ is the $S$-wave velocity at the surface $(z=0), \Delta V$ is the increment of the $S$-wave velocity at infinite depth, and $\alpha$ is the positive constant that determines the velocity-depth gradient. After applying the assumption of $\Delta V=3.2 \mathrm{~km} / \mathrm{s}$, which is the $S$-wave velocity of the bedrock according to the JIVSM, the local $S$-wave velocity structure in the Kanto Basin can be represented using only the bedrock depth and two parameters $\left(V_{0}\right.$ and $\alpha$ ) of this function. Figure 2 shows the $V_{0}$ and $\alpha$ dependency of the $S$-wave structure for sediment with a fixed $\Delta V=3.2 \mathrm{~km} / \mathrm{s}$. As shown in Figure 2, a variation of the two parameters can result in a wide variety of $S$-wave velocities at different depths.

\section{Conversion of the layered structure to a smooth depth-varying structure}

It may be useful to consider the conversion of the layered structure model to a smooth depth-varying structure model when constructing a $3 \mathrm{D}$ velocity model of sedimentary structure for long-period ground motion simulations. This is because many conventional

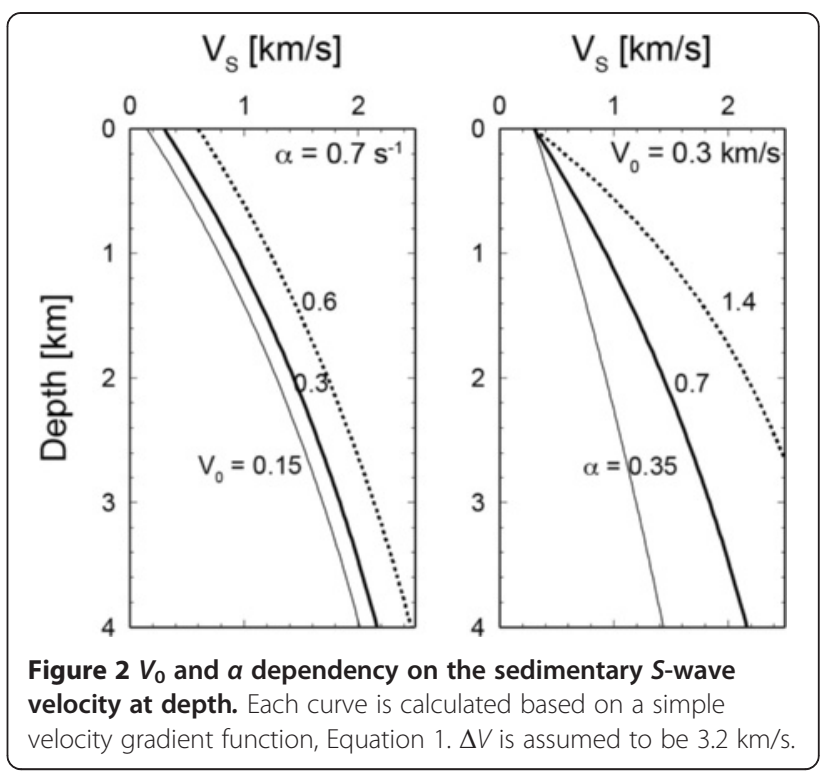

structure models were constructed by assuming a layered structure and it is difficult to compile these models, which are often represented by different medium parameters and numbers of layers.

From Equation 1, the one-way travel time of $S$ wave $\mathrm{t}(\mathrm{z})$ from $\mathrm{z}=0$ to a certain depth $z$ is analytically calculated as follows:

$$
t(z)=\frac{\Delta V}{\alpha\left(V_{0}+\Delta V\right)} \ln \frac{\left(V_{0}+\Delta V\right) \exp (\alpha z / \Delta V)-\Delta V}{V_{0}}
$$

To determine the appropriate values of $V_{0}$ and $\alpha$ for the conversion of a layered structure model, we defined a residual for the one-way $S$-wave travel times by the following equation:

$$
\text { Residual }=\frac{1}{N} \sum_{k=1}^{N}\left(t^{\mathrm{LSM}}\left(z_{k}\right)-t\left(z_{k}, V_{0}, \alpha\right)\right)^{2}
$$

where $z_{k}$ is the depth, $t^{\mathrm{LSM}}\left(z_{k}\right)$ is the one-way $S$-wave travel time of the layered structure model at the depth of $z_{k}, t\left(z_{k}, V_{0}, \alpha\right)$ is the one-way $S$-wave travel time with assumed $V_{0}$ and $\alpha$ at the depth of $z_{k}$ that is calculated using Equation 2, and $N$ is the total number of data points down to the depth of the bedrock. A simple grid search for $V_{0}$ and $\alpha$ can be performed to find the minimum residual and best-fit parameters, which represent the one-dimensional (1D) smooth depth-varying $S$-wave velocity structure of the sediments.

\section{$P$-wave velocity, density, and attenuation structure}

To construct velocity structure models for 3D FDM simulations, we adopted the modeling procedure used in 
Yoshimoto and Takemura (2014a). The $P$-wave velocity $\left(V_{P}\right)$ and density $(\rho)$ of sediment were assumed from the $S$-wave velocity using empirical relations reported by the Ministry of Education, Sports, Culture, Science and Technology (MEXT) (2007) and Shiomi et al. (1997), respectively.

Here, we employ the frequency-dependent $Q^{-1}$ model for $P$ and $S$ waves based on the formulations for FDM simulations of Robertsson et al. (1994). We adopt a single relaxation mechanism with a central frequency of $f_{0}=$ $1 \mathrm{~Hz}$, which gives a peak $Q^{-1}$ value at this frequency. Anelastic attenuation $(Q)$ values of the sediments for $P$ and $S$ waves were assumed using the empirical relation of Brocher (2008):

$$
\begin{aligned}
& Q_{\mathrm{S}}=-16+104.13 V_{\mathrm{S}}-25.225 V_{\mathrm{S}}^{2}+8.2184 V_{\mathrm{S}}^{3} \\
& Q_{\mathrm{P}}=2 Q_{\mathrm{S}}
\end{aligned}
$$

Other structures beneath the sediment, including the geometry of bedrock, the Moho, the PHS Plate, and the PAC Plate, were obtained from the JIVSM. The physical parameters of the JIVSM are shown in Table 1.

\section{Estimation of $V_{0}$ and $a$ near the edge of the northern Kanto Basin}

For modeling the velocity structure in the northern edge of the Kanto Basin where available geophysical data are sparse, we conducted 3D FDM simulations of the longperiod ground motions during the northern Tochigi earthquake $(M w=5.8)$ on 25 February 2013 and estimated the local values of $V_{0}$ and $\alpha$. We supposed that the local values of $V_{0}$ and $\alpha$ at a certain station near the basin edge could

Table $1 P$ - and $S$-wave velocities, densities, and anelastic

\begin{tabular}{|c|c|c|c|c|c|}
\hline Layer & $V_{P}[\mathrm{~km} / \mathrm{s}]$ & $V_{s}[\mathrm{~km} / \mathrm{s}]$ & $\rho\left[\mathrm{g} / \mathrm{cm}^{3}\right]$ & $Q_{P}$ & $\overline{Q_{S}}$ \\
\hline Sedimentary layer 1 & 1.8 & 0.5 & 1.95 & 170 & 100 \\
\hline Sedimentary layer 2 & 2.3 & 0.9 & 2.10 & 306 & 180 \\
\hline Sedimentary layer 3 & 3.0 & 1.5 & 2.25 & 510 & 300 \\
\hline Basement & 5.5 & 3.2 & 2.65 & 680 & 400 \\
\hline Upper crust & 5.8 & 3.4 & 2.70 & 680 & 400 \\
\hline Lower crust & 6.4 & 3.8 & 2.80 & 680 & 400 \\
\hline Upper mantle & 7.5 & 4.5 & 3.20 & 850 & 500 \\
\hline $\begin{array}{l}\text { Oceanic crust layer } 2 \\
\text { of PHS }\end{array}$ & 5.0 & 2.9 & 2.40 & 340 & 200 \\
\hline $\begin{array}{l}\text { Oceanic crust layer } 3 \\
\text { of PHS }\end{array}$ & 6.8 & 4.0 & 2.90 & 510 & 300 \\
\hline Oceanic mantle of PHS & 8.0 & 4.7 & 3.20 & 850 & 500 \\
\hline $\begin{array}{l}\text { Oceanic crust layer } 2 \\
\text { of PAC }\end{array}$ & 5.4 & 2.8 & 2.6 & 340 & 200 \\
\hline $\begin{array}{l}\text { Oceanic crust layer } 3 \\
\text { of PAC }\end{array}$ & 6.5 & 3.5 & 2.8 & 510 & 300 \\
\hline Oceanic mantle of PAC & 8.1 & 4.6 & 3.4 & 850 & 500 \\
\hline
\end{tabular}
attenuation of the JIVSM

Each parameter was obtained from Koketsu et al. (2008, 2009). be estimated from an existing velocity structure model if the simulated waveforms from the model successfully agree with the observed long-period ground motions.

The model used for the 3D FDM simulation covered an area of $135.6 \times 82.8 \mathrm{~km}^{2}$ in the horizontal directions (red dashed rectangle in Figure 1) and $52.5 \mathrm{~km}$ in depth, which was discretized by grid intervals of $0.15 \mathrm{~km}$ in the horizontal directions and $0.075 \mathrm{~km}$ in the vertical direction. The wave propagation in each grid point was calculated by solving equations of motions using a staggered-grid FDM with fourth-order and secondorder in space and time, respectively. With a minimum $S$-wave velocity $(0.3 \mathrm{~km} / \mathrm{s})$ and grid size $(0.15 \mathrm{~km})$, the FDM simulations can examine seismic wave propagation for periods longer than $4 \mathrm{~s}$ with sampling of eight grid points per minimum $S$ wavelength.

To perform an effective simulation, we employed a parallel 3D FDM simulation code based on a domainpartitioning procedure that utilizes a large number of processors with a message-passing interface (MPI) (e.g., Furumura and Chen 2004). We used a split-type perfectly matched layer (PML) absorbing boundary condition at the boundaries around the 3D model (e.g., Moczo et al. 2007; Maeda and Furumura 2013; Maeda et al. 2013a) to avoid artificial refractions from the 3D model boundaries, and a smoothing technique for layer interfaces near the PML boundaries was also applied for numerical stability (Maeda et al. 2013a).

The source depth of $8 \mathrm{~km}$, focal mechanism of the strike $/ \mathrm{dip} / \mathrm{rake}=168 / 86 /-10^{\circ}$, and seismic moment of $M_{0}=5.54 \times 10^{17} \mathrm{Nm}$ were assumed by referring to the Fnet centroid moment tensor (CMT) solution (Fukuyama et al. 1998; Okada et al. 2004). A source time function represented by the asymmetric cosine function (Ji et al. 2003) with $t_{\mathrm{s}}=0.3$ and $t_{\mathrm{e}}=2.7$ was adopted for a point seismic source. After the calculation, the $M_{0}$ value was adjusted to $77 \%$ of the CMT estimation to explain the observed $S$ wave amplitude at rock site TCG011 (K-NET Kuzuu) (Yoshimoto and Takemura 2014a).

\section{Results}

\section{Model construction}

\section{Local structure from VSP measurements}

Yoshimoto and Takemura (2014a) proposed a simple sedimentary velocity structure model of the Kanto Basin using VSP measurements at 14 deep boreholes (Yamamizu 1996, 2004). They reported that the 3D FDM simulations using this model were able to successfully reproduce the observed Love waves at seismic station SIT003 (K-NET Kuki; red triangle in Figure 1) in the northern Kanto Basin. Thus, we adopted the local $S$-wave velocity structures at 14 deep boreholes and SIT003 for our model construction. The values of $V_{0}$ and $\alpha$ at each site are listed in Table 2. 
Table 2 Estimated values of $V_{0}$ and $a$ at 14 deep boreholes and one K-NET station

\begin{tabular}{lllll}
\hline Site & Longitude & Latitude & $\boldsymbol{V}_{\mathbf{0}}[\mathbf{k m} / \mathbf{s}]$ & $\boldsymbol{a}\left[\mathbf{s}^{\mathbf{1}}\right]$ \\
\hline Mohka & 139.955 & 36.446 & 0.40 & 1.44 \\
Isesaki & 139.188 & 36.311 & 0.67 & 0.32 \\
Iwatsuki & 139.735 & 35.929 & 0.29 & 0.79 \\
Hidaka & 139.387 & 35.896 & 0.49 & 0.84 \\
Tokorozawa & 139.538 & 35.780 & 0.40 & 0.69 \\
Edosaki & 140.333 & 35.949 & 0.11 & 1.68 \\
Narita & 140.301 & 35.828 & 0.30 & 0.73 \\
Shimohsa & 140.024 & 35.793 & 0.30 & 0.69 \\
Chiba & 140.245 & 35.546 & 0.35 & 0.55 \\
Yohro & 140.156 & 35.283 & 0.56 & 0.59 \\
Futtsu & 139.859 & 35.341 & 0.38 & 0.73 \\
Fuchu & 139.470 & 35.654 & 0.46 & 0.53 \\
Yokohama & 139.523 & 35.496 & 0.43 & 0.74 \\
Atsugi & 139.357 & 35.401 & 0.17 & 2.67 \\
Kuki (SIT003) & 139.700 & 36.068 & 0.37 & 0.80 \\
\hline
\end{tabular}

Each value was estimated by Yoshimoto and Takemura (2014a).

Using these parameters, we constructed sedimentary seismic velocities, density, and the anelastic attenuation structure based on the procedure discussed in the previous section. For spatial interpolation of the values of $V_{0}$ and $\alpha$, we used a gridding algorithm 'surface' in the Generic Mapping Tools (Wessel and Smith 1998) software with a tension factor of 0.3 . To construct a $3 \mathrm{D}$ velocity structure model for whole depths, the structures beneath the sediments, including the topography of the bedrock, Moho, subducted oceanic plates, and mantle, were obtained from the JIVSM. Hereafter, we call this velocity structure model the 'initial model,' which was mainly constructed from the data of VSP measurements.

The spatial variations of $V_{0}$ and $\alpha$ of the initial model shown in Figure 3 seemed to be too smooth to represent the lateral variations of the sedimentary structure of the Kanto Basin. In spite of this, as shown in Figure 4, it was confirmed by our 3D FDM simulation that this model can be used practically to explain the observed longperiod ground motions (period of 4 to $8 \mathrm{~s}$ ) at eight stations near the basin edge (bold circles in the map of Figure 4). Figure 4 shows seismograms at only four stations, because simulated waveforms at four stations located near $\mathrm{TCH} .009$ are very similar to those at $\mathrm{TCH} .009$. Thus, we adopted the values of $V_{0}$ and $\alpha$ at these eight stations for the remaining process of our model construction.

\section{Local structure from JIVSM}

We converted the JIVSM layered sedimentary structure using the conversion procedure mentioned above. As an example, we briefly explain here how we derived the estimates of $V_{0}$ and $\alpha$ at site GNM.070. The JIVSM was constructed by three sedimentary layers (black line in Figure 5a), and its one-way $S$-wave travel time was a piecewise linear function (black line in Figure $5 \mathrm{~b}$ ). We employed a grid search procedure to find the minimum residual value using Equation 3. Figure 5c shows the distribution of normalized residuals in the model parameter space. Although there was trade-off involved in optimizing the two different parameters, the point of global minimum could be clearly detected in this plot. The one-way $S$-wave travel time curve and the $S$-wave velocity structure from the estimated parameters are shown in Figures 5b,a, respectively.

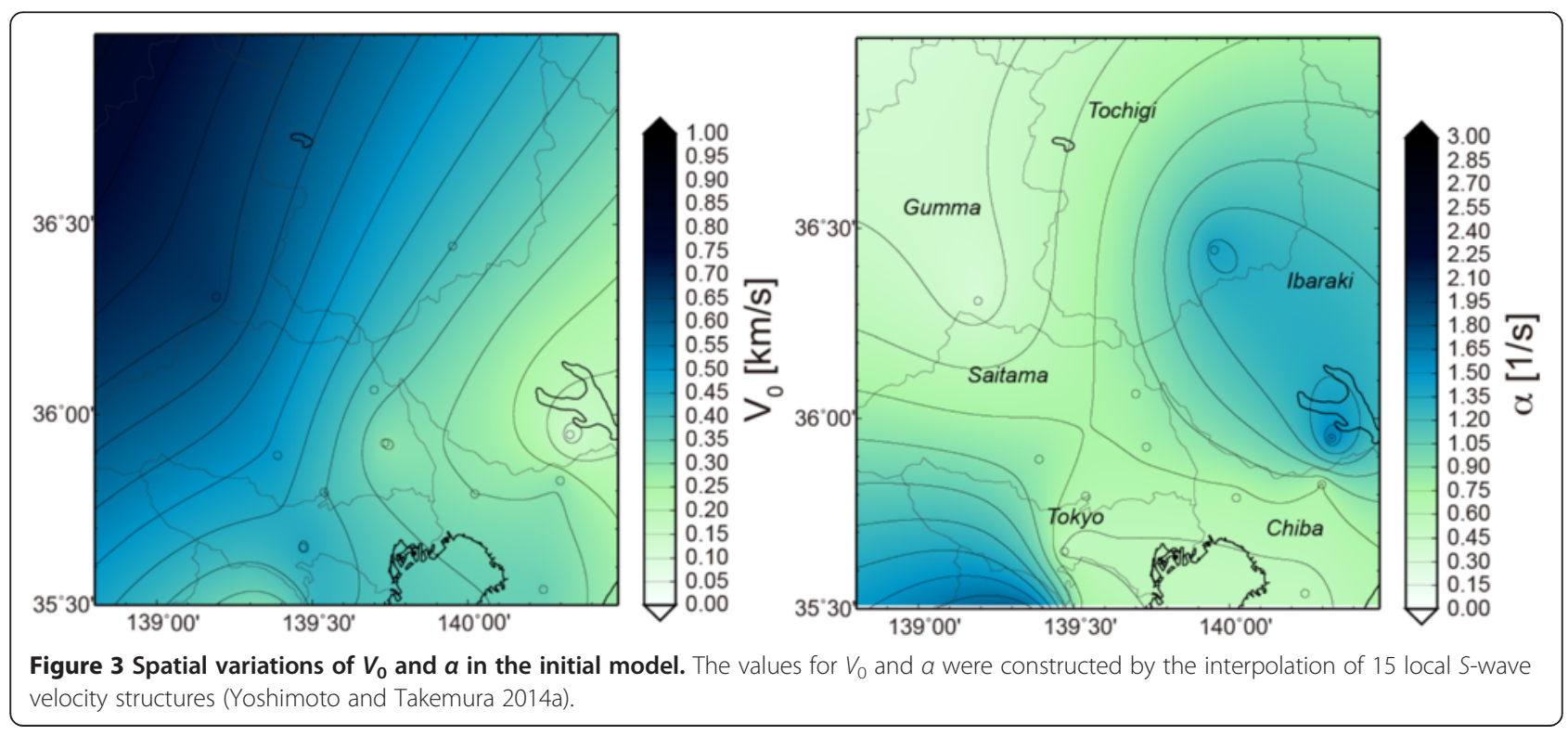



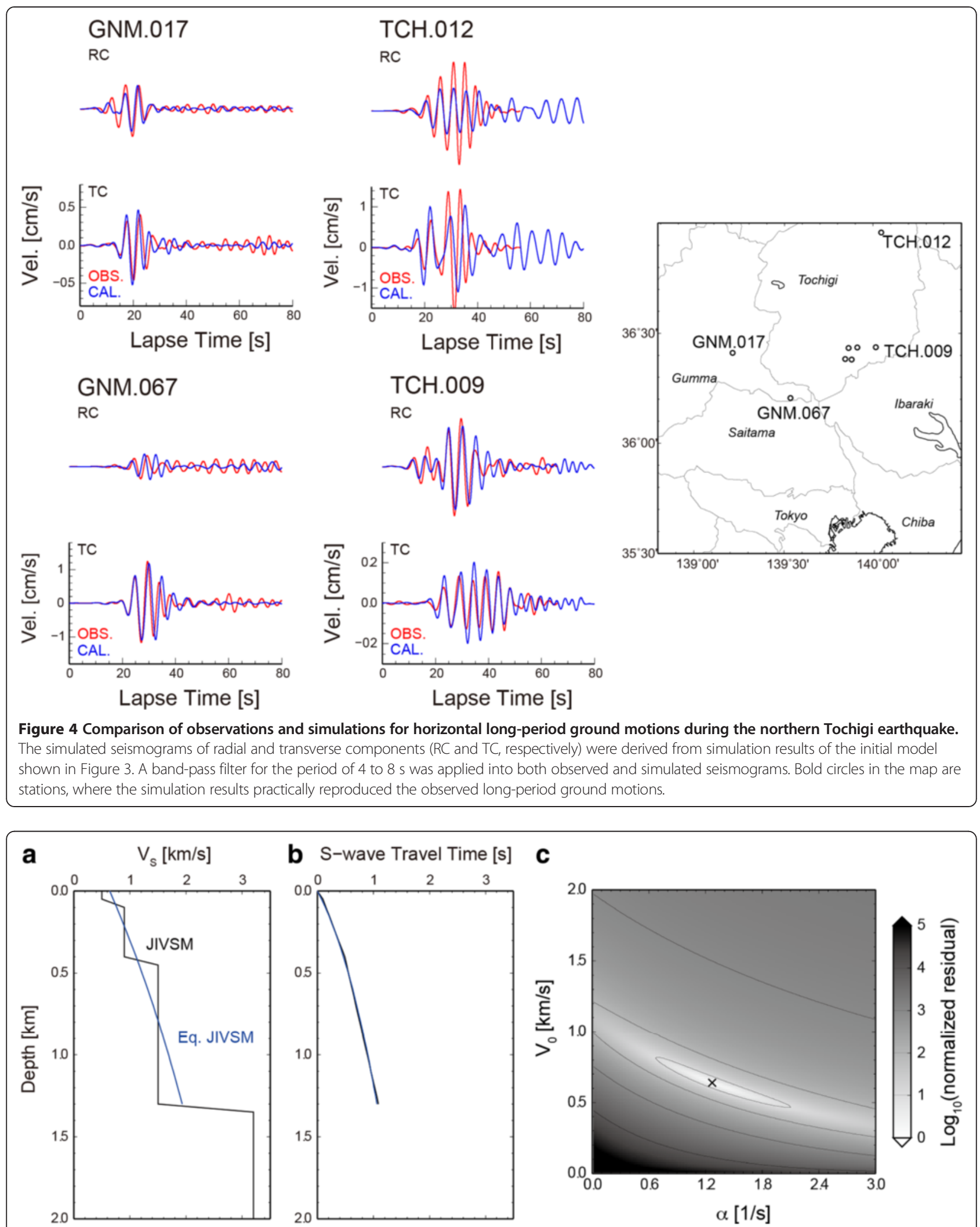

\section{b S-wave Travel Time [s] C}
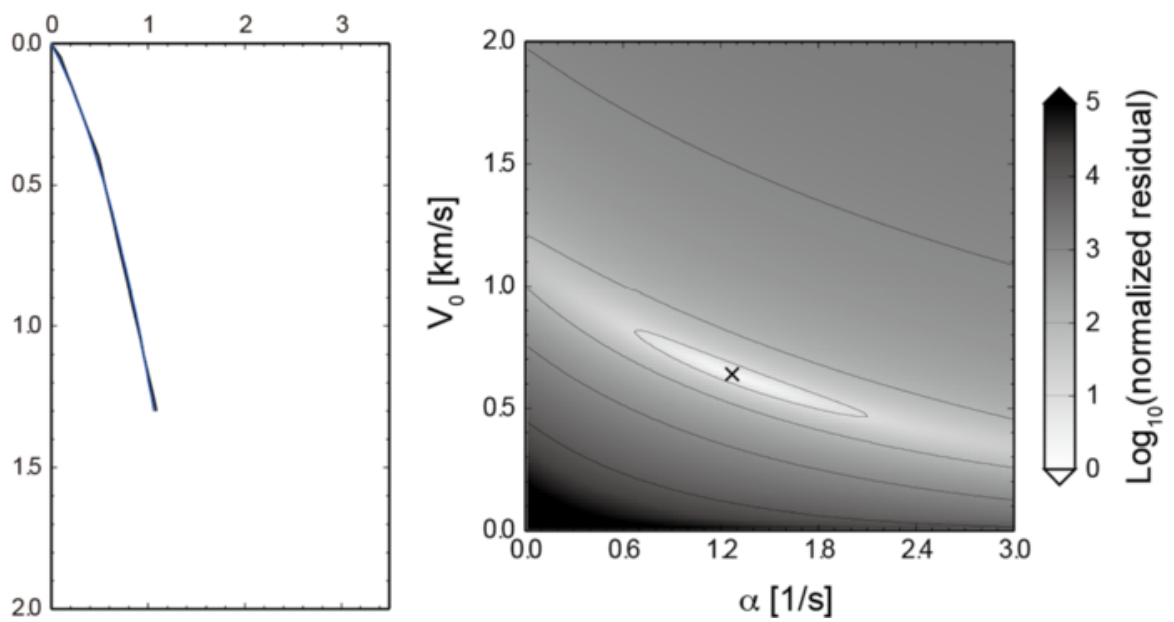

Figure 5 Estimation of $V_{0}$ and $a$ from a layered S-wave velocity structure at site GNM.070. (a) S-wave velocity structure of the layered structure (black line) and best-fit velocity gradient function (blue line). (b) One-way travel time of the layered structure (black line) and best-fit velocity gradient function (blue line). (c) Distribution of the normalized residual values calculated by Equation 3 for the model parameter space. 
Based on this conversion procedure, we estimated $V_{0}$ and $\alpha$ of the JIVSM in northern Kanto, where bedrock depths are larger than $1 \mathrm{~km}$. The estimated parameters were used to construct a smoothed sedimentary velocity structure model using the same interpolation technique mentioned in the construction of the initial model. Hereafter, we call the constructed smoothed sedimentary velocity structure model from the JIVSM the 'equivalent JIVSM (E. JIVSM)'.

We conducted a 3D FDM simulation of the long-period ground motion for the northern Tochigi earthquake using the E. JIVSM. Figure 6 shows the comparison of the horizontal long-period ground motions ( 4 to $8 \mathrm{~s}$ ) between the simulation of this model and the observational data. The simulation results of the E. JIVSM (Figure 6a) reproduced the observed long-period ground motions at seven stations near the edge of the northern Kanto Basin (bold circles in the lower right map of Figure 6b). Simulated waveforms of the E. JIVSM also showed high similarity to those of the JIVSM (Figure 6b). These results indicate that our conversion procedure is useful for the simulation of long-period ground motions. From these investigations, we adopted the values of $V_{0}$ and $\alpha$ at these seven stations for further analyses.

\section{Local structure from microtremor surveys}

We converted the layered sedimentary structure models from dense microtremor surveys in Saitama, Ibaraki, and Chiba (Matsuoka and Shiraishi 2002; Yamanaka et al. 2005; Senna et al. 2013) using the same conversion procedure discussed above. Since these models were derived from the dispersion analysis of surface waves, the incorporation of these models may improve the accuracy of long-period ground motion simulations. In this study, we converted 160 models (diamonds in Figure 7a), where the bedrock depths are larger than $0.5 \mathrm{~km}$, to allow for stable estimations of $\alpha$.

\section{$3 D$ velocity structure model by integration of local structures}

We integrated the estimated parameters at all of the sites mentioned above (Figure 7a) to construct a 3D velocity structure model of the sediment in the northern Kanto Basin (Figure 7b). Figure 7c shows the spatial variations of $V_{0}$ and $\alpha$ estimated by the interpolation, which used a total of 190 local site models. In Figure 7c, we found very complex lateral variations of the two parameters compared to the initial model (Figure 3). For example, high surface $S$-wave velocities $\left(V_{0}\right)$ appeared at the western side of the Kanto Basin and strong velocity increments against depth $(\alpha)$ were found in central Ibaraki. By adopting the same procedure that we used for constructing the initial model, we constructed a 3D velocity structure model for the $3 \mathrm{D}$ FDM simulation of long-period ground motions in this region. Hereafter, we call this model the 'smoothed basin velocity structure model (SBVSM)'. Figure 7d shows a comparison of the local $S$-wave velocity structures of the JIVSM, initial model, and SBVSM at three sites.

\section{Large-scale 3D FDM simulation of long-period ground motion in the northern Kanto Basin \\ Performance of the constructed model for the evaluation of long-period ground motion}

To demonstrate the performance of the SBVSM for the evaluation of long-period ground motions, we conducted large-scale 3D FDM simulations of long-period ground motions for two shallow moderate earthquakes. The model used for the 3D simulation covered an area of $153.6 \times 153.6 \mathrm{~km}^{2}$ in the horizontal directions (red solid square in Figure 1) and $60.0 \mathrm{~km}$ in depth. The scheme for the simulation was the same as that used for the previous simulations in this study.

One earthquake used in the simulations was the northern Tochigi earthquake, which was used for the parameter estimation near the basin edge. Here, we examine the propagation of the long-period surface wave in a wide area of the Kanto Basin, including the areas of Ibaraki, Saitama, Tokyo, and northern Chiba. Another earthquake was the northern Ibaraki earthquake $(M w=5.8)$ that occurred on 19 March 2011 at a depth of $5 \mathrm{~km}$. We employed these earthquakes to validate the SBVSM in Ibaraki and northern Chiba. For the latter earthquake, a focal mechanism of strike/dip/rake $=141 / 48 /-94^{\circ}$ and seismic moment $M_{0}=6.35 \times 10^{17} \mathrm{Nm}$ were assumed by referring to the F-net CMT solution. A source time function represented by the asymmetric cosine function (Ji et al. 2003) with $t_{\mathrm{s}}=0.3$ and $t_{\mathrm{e}}=2.7$ was adopted. After the calculation, the $M_{0}$ value of this event was adjusted to $77 \%$ of the CMT estimation to explain the observed $S$ wave amplitude at rock site IBRH19 (KiK-net Tsukuba).

Figure 8 shows a comparison of the simulated and observed horizontal long-period ground motions for the northern Tochigi earthquake. We also conducted a FDM simulation using the JIVSM as a reference. The simulation result of the JIVSM (black lines) showed large discrepancies with the observed seismograms in terms of arrival times, amplitudes, and durations. Large-amplitude surface waves arrived earlier compared to the observations, especially at TCG001, SIT003, and IBRH10. In addition, the amplitudes of the surface waves were overestimated at SIT.015, SIT010, and SIT003. Furthermore, we confirmed that the JIVSM did not reproduce the observed excitation of the long-period surface waves at the northern edge of the Kanto Basin (TCG001, TCGH06, and SIT003). In contrast, simulation results of the SBVSM accurately reproduced the observed amplitudes and arrival times 


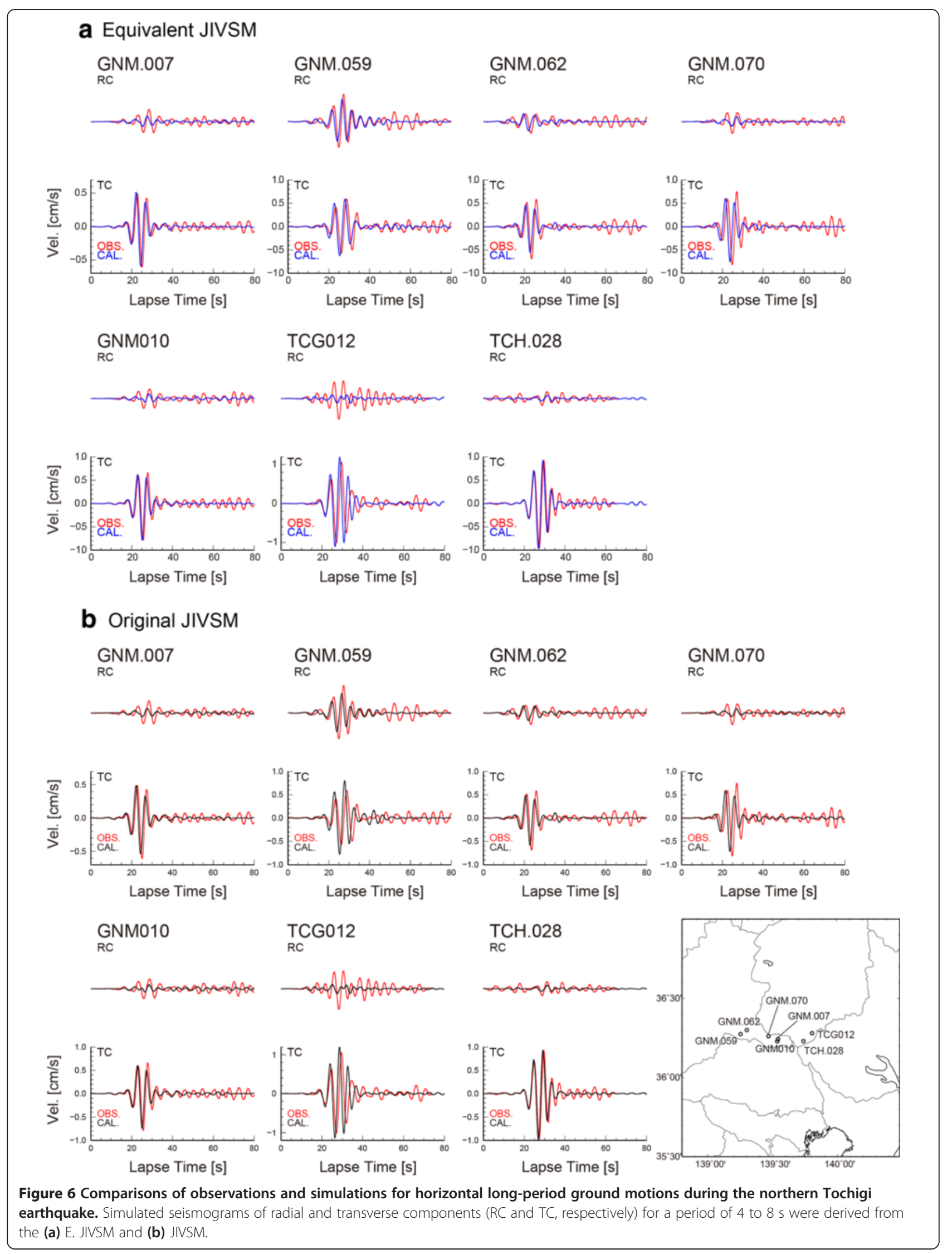




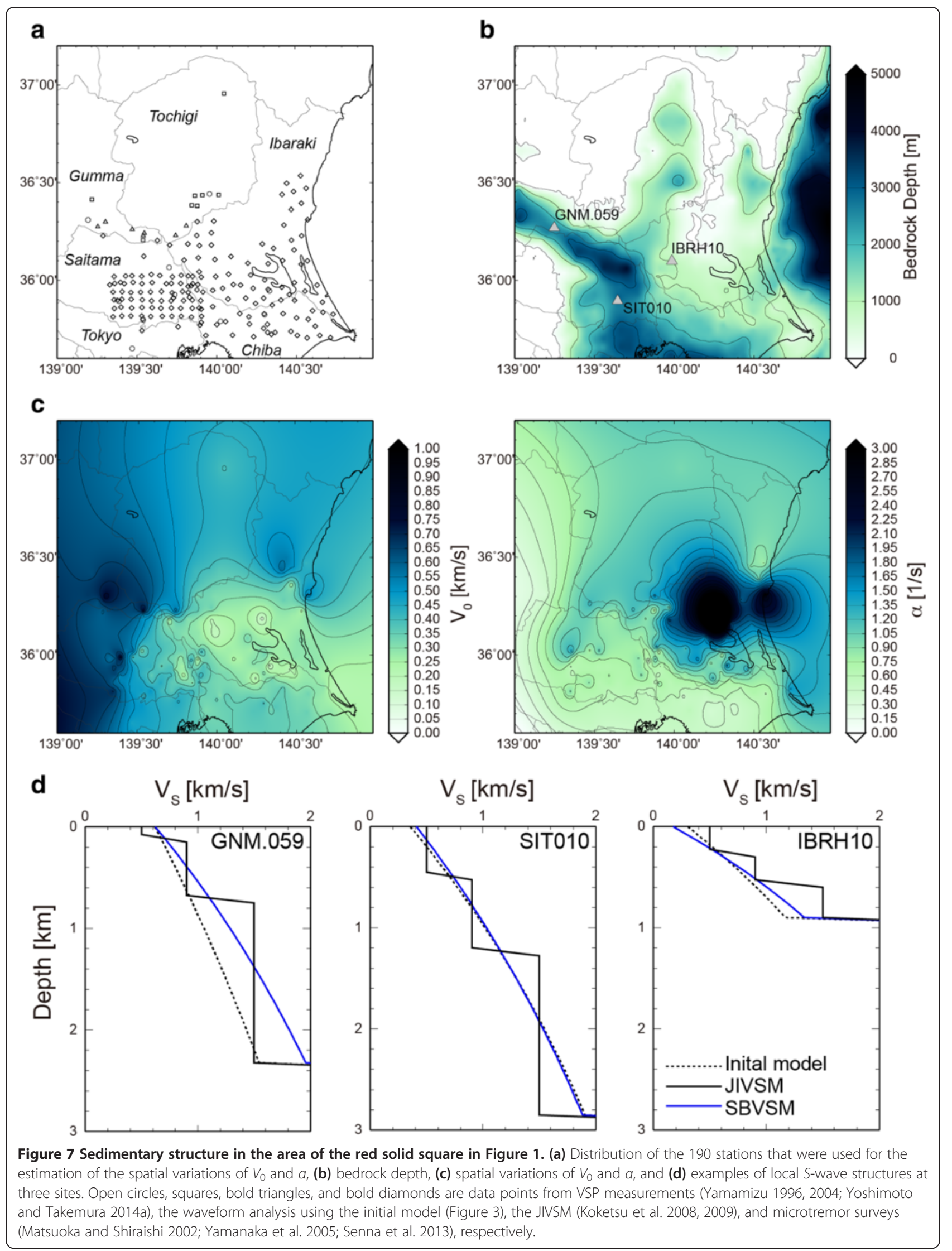




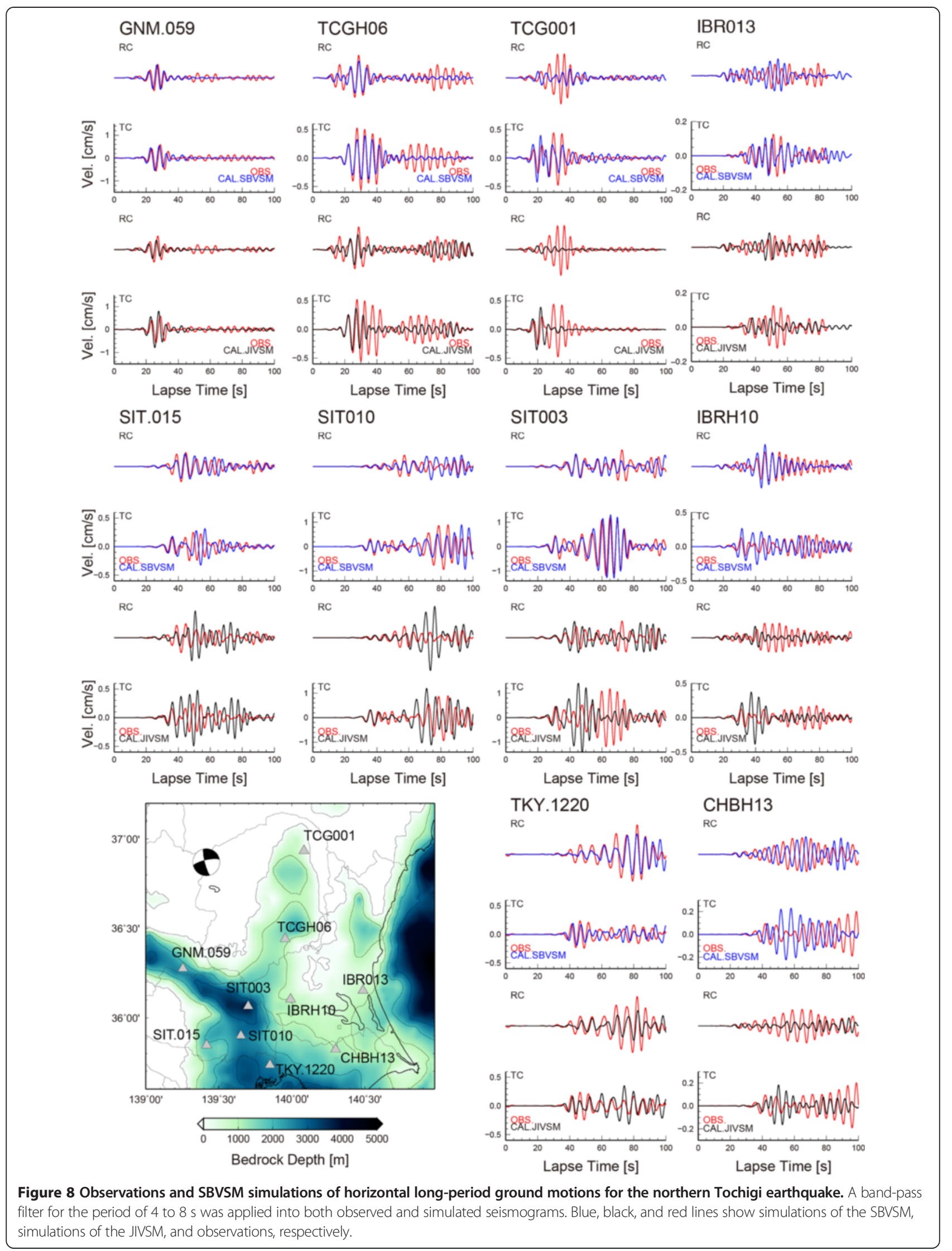


of surface waves at not only stations near the basin edge (GNM.059, TCGH06, TCG001, and SIT003) but also at stations far from the edge (SIT.015, SIT010, and TKY.1220). A high reproducibility of the observed long-period ground motion at the middle and eastern parts of the Kanto Basin may be achieved by incorporating the $S$-wave velocity structures derived from dense microtremor surveys in Saitama, Ibaraki, and northern Chiba.

The SBVSM also performed well during the evaluation of the long-period ground motion for the northern Ibaraki earthquake, which was not used in the parameter estimations; additionally, this earthquake occurred in a different back azimuth compared to the northern Tochigi earthquake. Figure 9 shows a comparison of the simulated and observed horizontal long-period ground motions for this earthquake. Significant differences were not found between the results from the two structure models in the area of shallow bedrock depths (IBR012 and IBRH19). However, simulated waveforms of the JIVSM in deep sediment areas (SIT.081, SIT003, SITH01, and CHB002) were overestimated. Simulated waveforms of the SBVSM reproduced the observed amplitudes and arrival times of the long-period surface waves in the northern Kanto Basin very accurately.

\section{Surface wave propagation in the northern Kanto Basin}

Since simulated waveforms of the SBVSM accurately reproduced the observed waveforms in the northern Kanto Basin (Figures 8 and 9), it was concluded that our simulations succeeded in reproducing the excitation and propagation of surface waves in this area. Thus, using these simulated and observed waveforms, we investigated the characteristics of the excitation and propagation of the long-period surface waves during two shallow moderate earthquakes in detail.

Figure 10 shows snapshots of the seismic wave propagation for a period of 4 to $8 \mathrm{~s}$ derived from simulations of the SBVSM for the two earthquakes. The spatial variation of the amplitudes at each time step was calculated by the interpolation of the root mean square amplitude of the simulated horizontal seismograms observed at virtual seismic stations, which were uniformly distributed at an interval of $3 \mathrm{~km}$.

In an early snapshot of the northern Tochigi earthquake ( $t=30 \mathrm{~s}$; Figure 10a), strong surface wave excitation around the Gumma-Saitama border (mark A) was observed. The excited surface waves propagated towards the middle part of the Kanto Basin, and they had a complex propagation pattern. At a lapse time of $t=50$ to $80 \mathrm{~s}$, the surface waves near the Saitama-Chiba border (mark B) were propagating much slower than the surface waves propagating in the midst of Saitama (mark C). In the later frames $(t=70$ to $80 \mathrm{~s}$ ), very slow surface waves (mark B) propagated towards Tokyo and Chiba while preserving their large amplitudes and shapes of wave packets.

Figure 10b shows the seismic wave propagation during the northern Ibaraki earthquake. At a lapse time of $t=$ $45 \mathrm{~s}$, large-amplitude surface waves were excited at the Ibaraki-Chiba border (mark D), and consequently, these waves propagated towards central Chiba. There was a significant dispersion of surface waves at northern Chiba (mark E), and these showed a delay of the largeamplitude arrival, which was confirmed with the observed seismograms at $\mathrm{CHBH} 13$ (lower right part of Figure 9).

From the snapshots of both earthquakes, we determined that the excitation of the surface waves occurred effectively at the area with a bedrock depth of approximately $1 \mathrm{~km}$ (e.g., at mark A and mark D in Figure 10). The excited surface waves propagated in the laterally inhomogeneous sedimentary basin and displayed complicated behaviors of propagation, especially for the northern Tochigi earthquake (mark B and mark $C$ in Figure 10a). A conventional Fourier analysis revealed that the dominant period of the surface waves was approximately $6 \mathrm{~s}$.

Figure 11 shows the velocity seismograms of the transverse component at the stations aligned along the propagation path of phases $\mathrm{C}$ and $\mathrm{B}$ in the middle and eastern parts of Saitama. In the aligned seismograms, we confirmed both the faster phase $C$ and slower phase $B$ as seen in Figure 10a, and these phases were reproduced by our 3D FDM simulation.

To interpret this observation, we evaluated the twodimensional (2D) map of the group velocity of fundamental Love waves for the periods of $4,5,6,7$, and $8 \mathrm{~s}$ using the codes developed by Herrmann (2013). The 1D velocity structure of the SBVSM at each site was used for constructing this map. Figure 12 illustrates the 2D map of the group velocities for each period, and these maps show strong lateral variation in the Kanto Basin. The map of group velocity for the period of $6 \mathrm{~s}$ successfully explains the propagation speed of both phases in the observations and simulations.

In Figures 10 and 11, large-amplitude Love waves stably propagated towards the southern part of the Kanto Basin, preserving large amplitudes and shapes of distinct wave packets. Similar observations of distinct surface waves have been reported in previous studies (e.g., Furumura and Hayakawa 2007; Hayakawa 2009). To clarify the cause of the observed stable propagation of Love waves in the inhomogeneous Kanto Basin, we examined the detailed period dependency of the Love wave group velocity beneath the linear array. Figure 13 shows the Love wave group velocities as a function of the period derived from the local $S$-wave velocity 


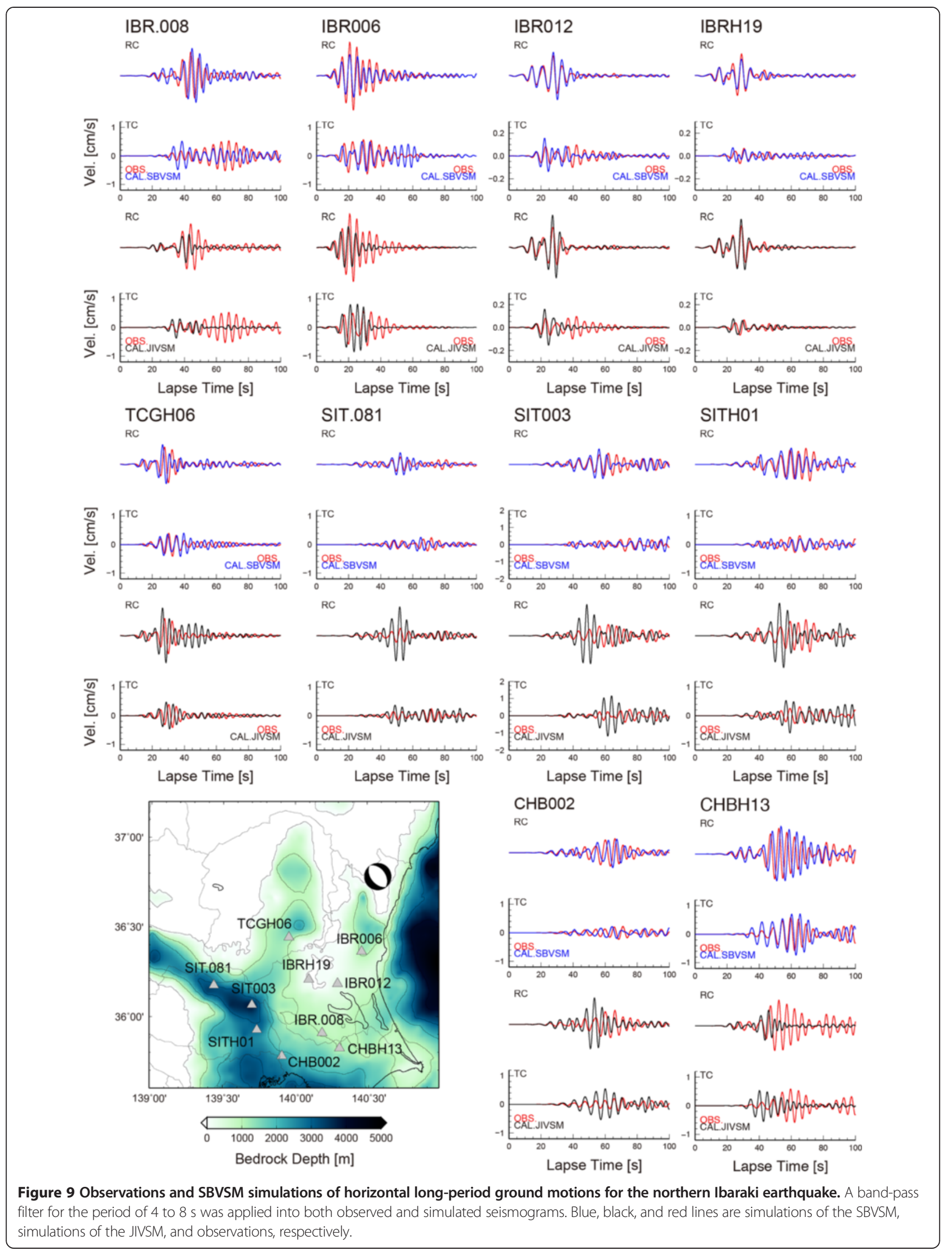




\section{a Northern Tochigi earthquake}

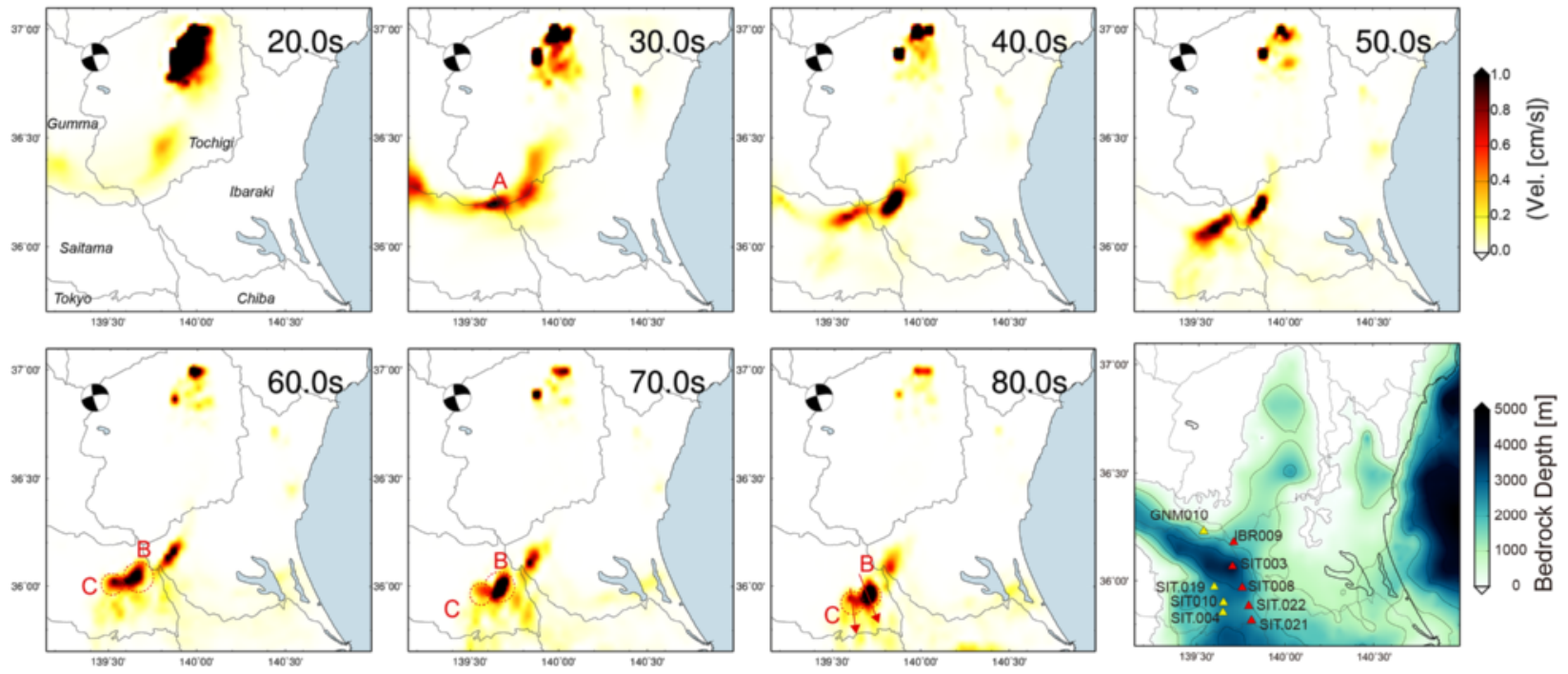

b Northern Ibaraki earthquake

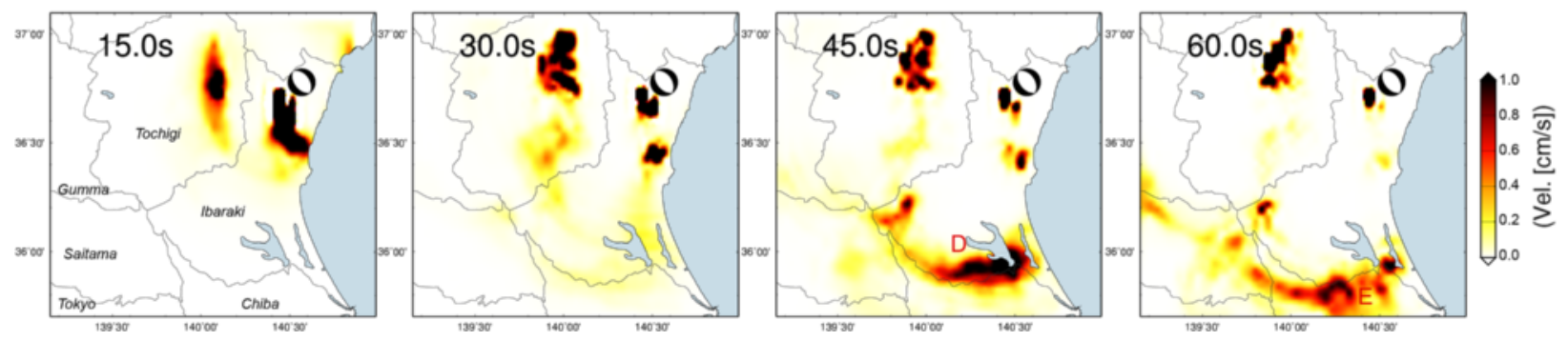

Figure 10 Snapshot of the propagation of simulated long-period ground motions (period of $\mathbf{4}$ to 8 s). Simulations of the (a) northern Tochigi earthquake and (b) northern Ibaraki earthquake. The spatial variation of bedrock depth is also shown in lower right part of (a). The red arrows denote the propagation directions of phases $B$ and $C$.

structures beneath the linear array of eastern Saitama. The evaluated group velocities displayed very weak period dependency at and around the dominant period of the observed Love waves (6 s), especially at SIT.021 and SIT.022. This may be the reason why the observed and simulated Love waves stably propagated without strong dispersion and, consequently, preserved their shapes of wave packets.

\section{Discussion}

Anelastic attenuation of sediments is an important factor for the amplification of long-period ground motion in sedimentary basins. In this study, we employed $Q$ values estimated by a simple empirical relation (Brocher 2008) and a frequency-dependent $Q^{-1}$ model for $P$ and $S$ waves with a central frequency of $f_{0}=1 \mathrm{~Hz}$ based on the formulations for FDM simulations of Robertsson et al. (1994). Here, we discuss the effect of the anelastic attenuation of the sediments on the modeling of longperiod ground motions.
Figure 14a shows the frequency-dependent $Q_{S}^{-1}$ (black line) assumed in the simulations, which was obtained from the JIVSM sedimentary layer 2 (see Table 1) and Brocher's empirical relation with various central frequencies (navy blue lines). Brocher $Q_{S}{ }^{-1}$ values were calculated using $V_{S}=0.9 \mathrm{~km} / \mathrm{s}$, which corresponds to the $S$-wave velocity of JIVSM layer 2 . The attenuation of Brocher $Q_{S}{ }^{-1}$ is approximately three times stronger than that of the JIVSM $Q_{S}^{-1}$ if the same central frequency is assumed. If we employ a lower central frequency $\left(f_{0}=0.5 \mathrm{~Hz}\right)$, very strong attenuation can be expected for the frequency range of long-period ground motion (pink area in Figure 14a).

To investigate the optimal $Q_{S}$ values for long-period ground motions, we conducted additional FDM simulations of long-period ground motions using the central frequencies of $f_{0}=0.5,1$, and $2 \mathrm{~Hz}$. Figure $14 \mathrm{~b}$ shows a comparison of the simulated and observed waveforms of the transverse component (period of 4 to $8 \mathrm{~s}$ ) at SIT003 (red triangle in Figure 1) during the northern Tochigi earthquake. The simulation results demonstrated that 

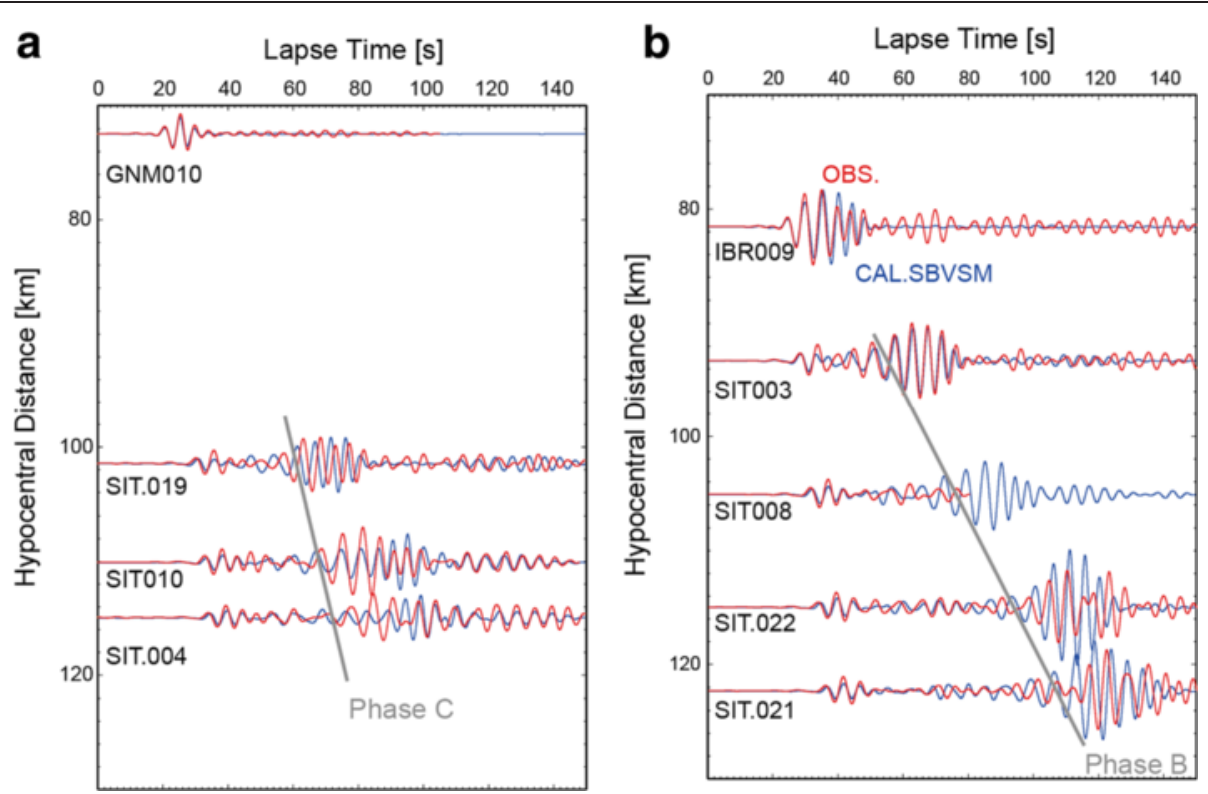

Figure 11 Aligned transverse velocity seismograms for the period of 4 to $8 \mathrm{~s}$. Seismograms were recorded at (a) stations in middle Saitama (yellow triangles in Figure 10a) and (b) stations in eastern Saitama (red triangles in Figure 10a) during the northern Tochigi earthquake. Blue and red lines are simulations of the SBVSM and observations, respectively.

the central frequency of $Q_{S}$ affected the amplitude of the later part of the surface wave packet (period of approximately $4 \mathrm{~s}$ ), whereas no apparent effects appeared for the earlier part and dispersion feature of the Love wave. By comparing these results with the observed seismogram, the most preferable value of the central frequency was $1 \mathrm{~Hz}$, which was used in the 3D FDM simulations in this study.

Although we proposed a new 3D velocity structure model for the evaluation of the long-period ground
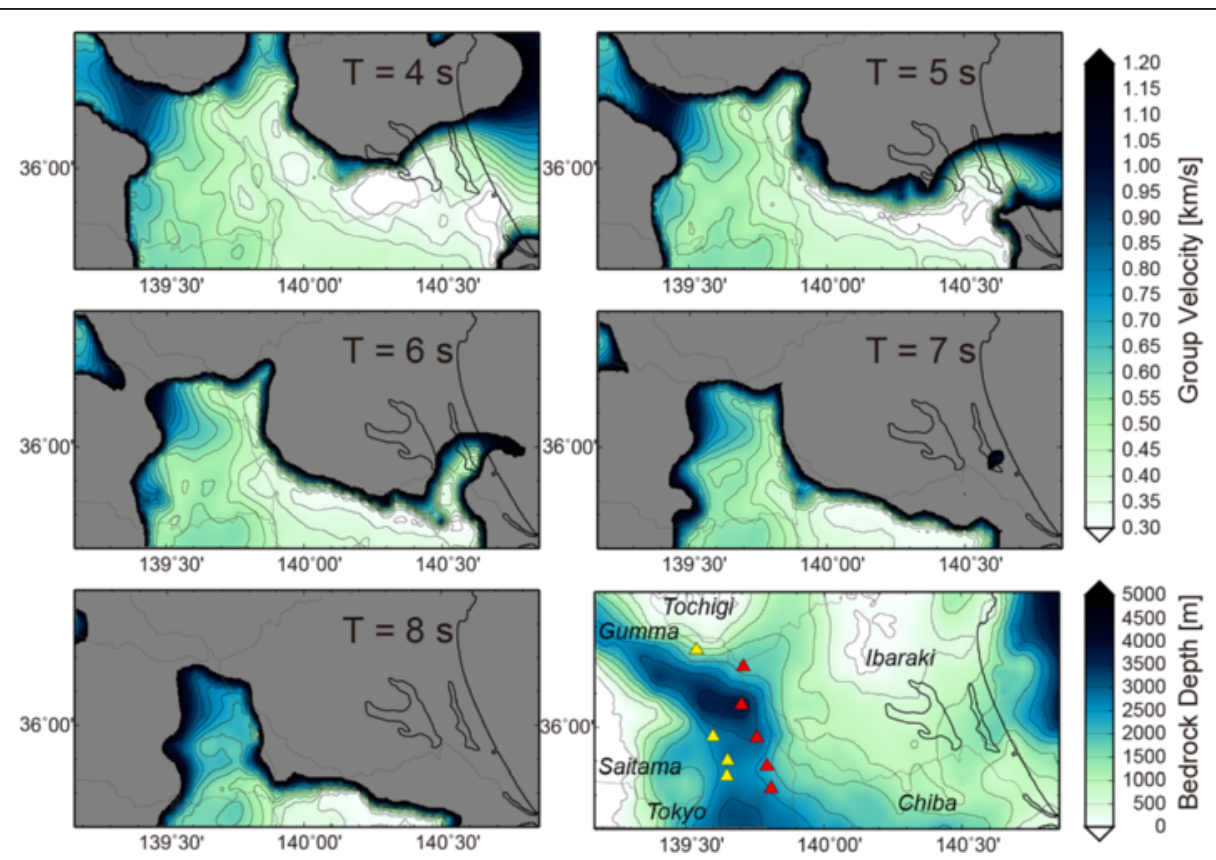

Figure 12 Spatial variation of Love wave group velocity for periods $(\boldsymbol{T})$ of $\mathbf{4}$ to $\mathbf{8} \mathrm{s}$. The local group velocities of Love waves were derived from the SBVSM. The spatial variation of the bedrock depth is also shown in the lower right panel. The areas, where group velocities are larger than $1.2 \mathrm{~km} / \mathrm{s}$, were masked. The group velocities for each period were calculated using codes developed by Herrmann (2013). Plotted stations in the map of bedrock depth are the same as those used in Figure 10. 


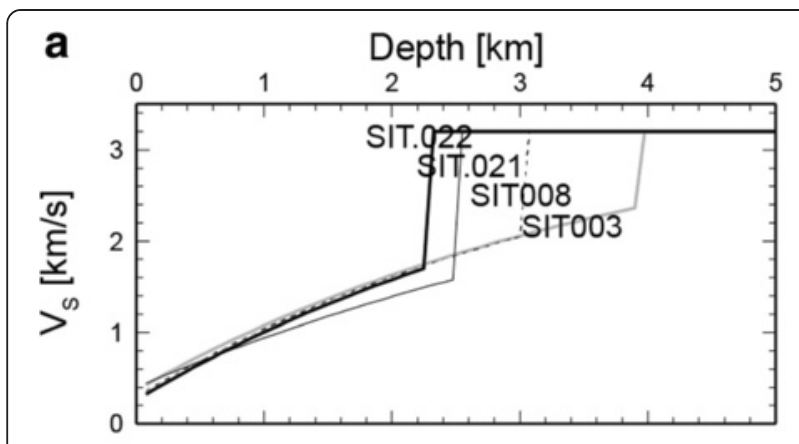

b

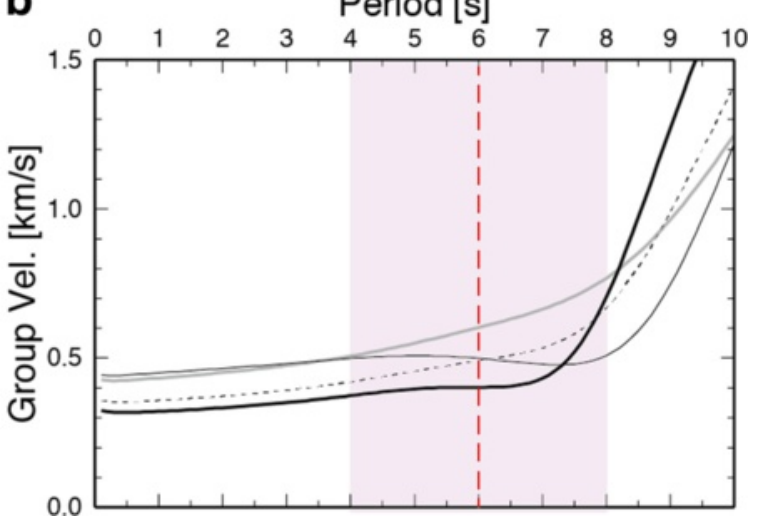

Figure 13 Group velocity of Love waves as a function of the period. (a) Local S-wave velocity structures from the SBVSM and (b) period-dependent group velocity of the fundamental Love wave at each station. Stations are shown in the lower right part of Figure 10a. Red dashed line represents the dominant period of the distinct Love wave packet during the northern Tochigi earthquake. Group velocities were calculated using codes developed by Herrmann (2013).

motions in the northern Kanto Basin, it may not be acceptable for short-period ( $<1$ s) seismic wave propagation because of the lack of small-scale velocity heterogeneities. The original $S$-wave velocity structure obtained by VSP measurements has rich shorter wavelength components of the velocity heterogeneities (Yamamizu 1996, 2004; Shiomi et al. 1997). To achieve precise simulations that are capable of reproducing shorter-period seismic waves, such as for the evaluation of the peak ground acceleration and scattering in the Kanto Basin, we should revisit the original results from the VSP measurements and the small-scale velocity heterogeneities should be embedded in the model.

In this study, we used only one earthquake for the estimation of the local structural parameters $\left(V_{0}\right.$ and $\alpha$ ) near the basin edge. It would have been better to use more earthquakes distributed in a wide azimuthal range for precise estimations. However, there were very few relevant moderate earthquakes ( $M w$ approximately 6$)$ that occurred near the basin edge. Hence, it would be useful to validate and reconstruct the SBVSM using various azimuthal events in future studies.
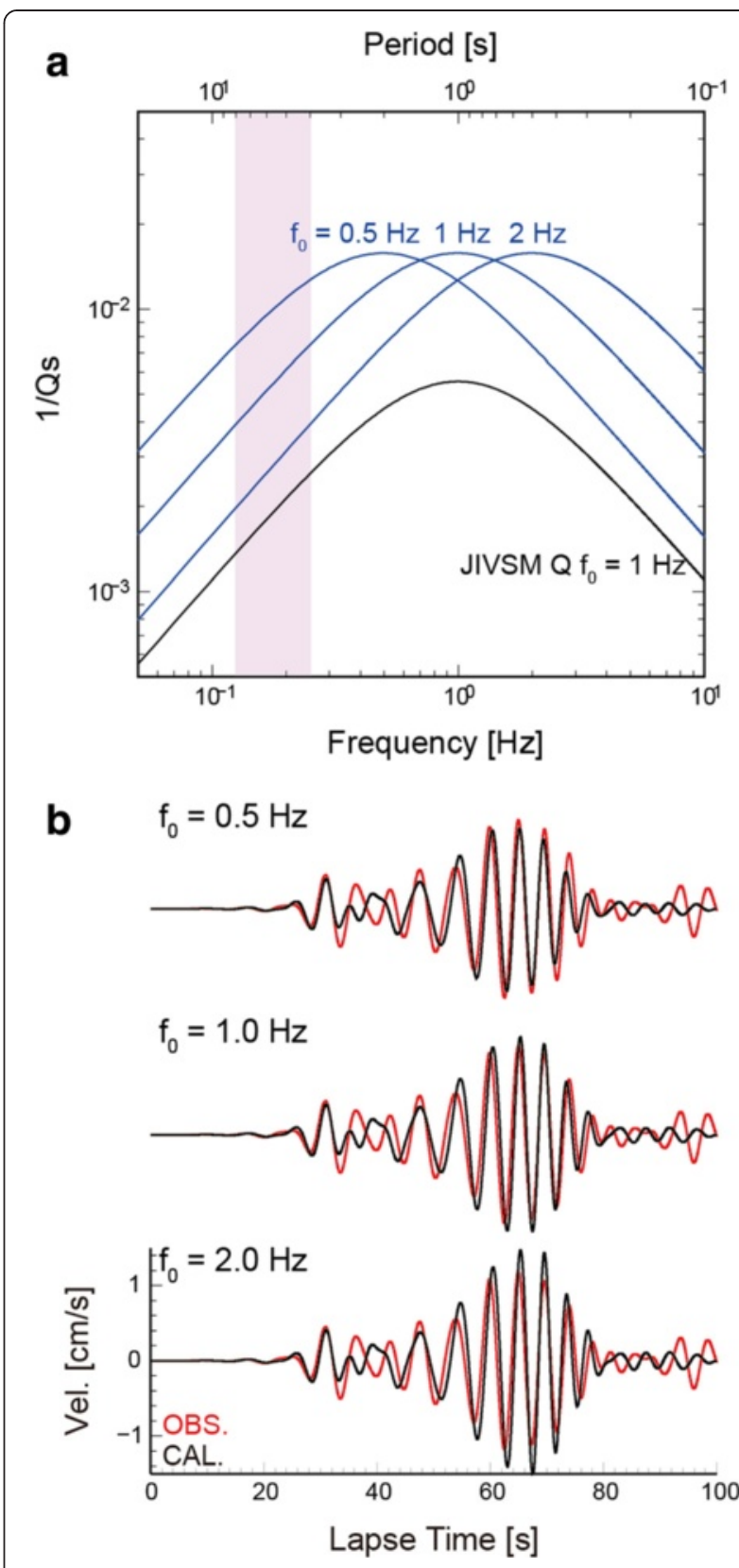

Figure 14 Effect of frequency-dependent $Q_{s}^{-1}$ on simulated seismograms. (a) Frequency dependence of $Q_{S}^{-1}$ derived from the $J$ JVSM $Q_{S}$ of sedimentary layer 2 (black line) and the Brocher $Q_{S}$ relation assuming $V_{S}=0.9 \mathrm{~km} / \mathrm{s}$ (navy blue lines). (b) Velocity seismograms of the transverse component at SIT003 for frequencies of $0.125-0.25 \mathrm{~Hz}$ (period of 4 to $8 \mathrm{~s}$ ) derived from simulation results of the northern Tochigi earthquake with various central frequencies of $Q_{S}{ }^{-1}$. The pink area in (a) represents the target frequency range in our study.

In the Kanto Basin, the sedimentary structure of the JIVSM was mainly constructed using geophysical information from refraction surveys (Koketsu et al. 2008, 2009). However, the refraction surveys were not densely carried out in the northern part of the Kanto Basin compared with the middle and southern parts. Thus, the 
JIVSM did not reproduce the observed long-period ground motion very well, especially for excitation near the basin edge. In contrast, by introducing dense geophysical data around the northern Kanto Basin (see Figure 7a), the SBVSM was able to reproduce the observed excitation and propagation of long-period surface waves. We believe that the incorporation of data from denser microtremor surveys has the potential to improve the reproducibility of the observed long-period ground motions in the Kanto Basin. In addition, precise information on the bedrock depths, which was not discussed in this study, should be required for more confident evaluations in future studies.

\section{Conclusions}

For practical evaluations of the long-period ground motions (period of 4 to $8 \mathrm{~s}$ ), we constructed a 3D velocity structure model of the northern Kanto Basin using a simple velocity gradient function. Our structure model SBVSM, which was constructed from a waveform analysis and dense geophysical data from VSP measurements, the JIVSM, and the microtremor surveys showed strong lateral inhomogeneities in this basin. The largescale 3D FDM simulations using the SBVSM model accurately reproduced the observed long-period ground motions during two moderate earthquakes that occurred in the northern Kanto region. Hence, these results show the adequacy of our modeling procedure.

By comparing the simulations and observations, it was found that the observed long-period ground motions were generated by the long-period surface waves excited at the basin edge, where the bedrock depths are approximately $1 \mathrm{~km}$. The excited surface waves propagated towards the central or southern parts of the Kanto Basin, and they showed complicated propagation patterns with large-amplitude, distinct, long-period wave packets. Our results strongly indicate that it is necessary to consider the strong lateral variation of the sedimentary velocity structure to better understand the complex propagation characteristics of the surface waves in this basin.

\section{Competing interests}

The authors declare that they have no competing interests.

\section{Authors' contributions}

ST conducted the large-scale 3D FDM simulations, analyzed both simulated and observed seismograms, and drafted this manuscript. MA conducted 3D FDM simulations for modeling the velocity structures near the northern edge of the Kanto Basin. KM carried out the conversions of layered structures derived from microtremor surveys to smoothed depth-gradient structures. KK carried out the theoretical analysis of long-period surface wave propagation in the Kanto Basin. KY surveyed the available geophysical data and helped draft this manuscript. All authors approved the final manuscript.

\section{Acknowledgements}

We would like to thank two anonymous reviewers and the editor, H. Takenaka, for constructive comments that improved an earlier draft of this manuscript. We acknowledge the National Research Institute for Earth Science and Disaster Prevention, Japan (NIED) for providing the KiK-net and K-NET waveform data and the CMT solutions from the F-net. We also used SK-net waveform data that were provided by the Earthquake Research Institute, the University of Tokyo. The FDM simulations of seismic wave propagation were conducted on the computer system of the Earthquake and Volcano Information Center at the Earthquake Research Institute, the University of Tokyo. One of the authors, ST, is grateful for the financial support provided by a Grant-in-Aid from JSPS (the Japan Society for Promotion of Science; No. 24.5704). All figures in the present study were drawn using the Generic Mapping Tools software package developed by Wessel and Smith (1998).

\section{Author details}

${ }^{1}$ Department of Material System Science, Graduate School of Nanobioscience, Yokohama City University, 22-2, Seto, Kanazawa-ku, Yokohama 236-0027, Japan. ²Division of Sciences, International College of Arts and Sciences, Yokohama City University, 22-2, Seto, Kanazawa-ku, Yokohama 236-0027, Japan.

Received: 19 July 2014 Accepted: 31 January 2015

Published online: 01 March 2015

\section{References}

Asano K, Iwata T (2012) Source model for strong ground motion generation in the frequency range $0.1-10 \mathrm{~Hz}$ during 2011 Tohoku earthquake. Earth Planets Space 64:1111-1123, doi:10.5047/eps.2012.05.003

Beck JL, Hall JF (1986) Factors contributing to the catastrophe in Mexico City during the earthquake of September 19, 1985. Geophys Res Lett 13:593-596, doi:10.1029/GL013i006p00593

Brocher TM (2008) Key elements of regional seismic velocity models for long period ground motion simulations. J Seismol 12:217-221, doi:10.1007/ s10950-007-9061-3

Fujiwara H, Kawai S, Aoi S, Morikawa N, Senna S, Kudo N, Ooi M, Hao KX-S, Hayakawa Y, Toyama N, Matsuyama N, Iwamoto K, Suzuki H, Ei R (2009) A study on subsurface structure model for deep sedimentary layers of Japan for strong-motion evaluation. Technical note of the National Research Institute for Earth Science and Disaster Prevention, No 337 (in Japanese)

Fukuyama E, Ishida M, Dreger DS, Kawai H (1998) Automated seismic moment tensor determination by using on-line broadband seismic waveforms. Zisin 51:149-156, in Japanese with English abstract

Furumura T, Chen $L$ (2004) Large scale parallel simulation and visualization of 3-D seismic wavefield using Earth simulator. Comput Model Eng Sci 6:153-168, doi:10.3970/cmes/2004.006.153

Furumura T, Hayakawa T (2007) Anomalous propagation of long-period ground motions recorded in Tokyo during the 23 October $2004 M_{w} 6.6$ Niigata-ken Chuetsu, Japan, Earthquake. Bull Seismol Soc Am 97:863-880, doi:10.1785/0120060166

Furumura T, Takemura S, Noguchi S, Takemoto T, Maeda T, Iwai K, Padhy S (2011) Strong ground motions from the 2011 off-the Pacific-Coast-of-Tohoku, Japan $(M w=9.0)$ earthquake obtained from a dense nationwide seismic network. Landslides 8:333-338, doi:10.1007/s10346-011-0279-3

Hayakawa T (2009) Generation and propagation of the long-period ground motion in the Kanto basin: dense seismic-network analysis and large-scale numerical simulations. PhD Dissertation, The University of Tokyo, Japan (in Japanese with English abstract)

Herrmann RB (2013) Computer programs in seismology: an evolving tool for instruction and research. Seismol Res Lett 84:1081-1088, doi:10.1785/0220110096

Horikawa H, Yoshimi M, Sekiguchi H, Yoshida K, Sugiyama Y, Satake K, Fukuwa N, Suzuki H, Matsuyama H, Ying L, Takizawa F (2008) A three-dimensional subsurface structure model of the Chukyo area, central Japan. Annual report on active fault and paleoearthquake researches. Geol Surv Jpn 8:203-254, in Japanese with English abstract

Iwaki A, Iwata T (2010) Simulation of long-period ground motion in the Osaka sedimentary basin: performance estimation and the basin structure effects. Geophys J Int 181:1062-1076, doi:10.1111/j.1365-246X.2010.04556.x

Iwaki A, Morikawa N, Maeda T, Aoi S, Fujiwara H (2013) Finite-difference simulation of long-period ground motion for the Sagami Trough megathrust earthquakes. J Disast Res 8(5):926-940

Ji C, Helmberger DV, Wald DJ, Ma KF (2003) Slip distribution and dynamic implication of the 1999 Chi-Chi, Taiwan earthquake. J Geophys Res 108:2412, doi:10.1029/2002JB001764

Kinoshita S (1998) Kyoshin net (K-NET). Seismol Res Lett 69:302-332

Kinoshita S, Fujiwara H, Mikoshiba T, Hoshino T (1992) Secondary Love waves observed by a strong-motion array in the Tokyo lowlands, Japan. J Phys Earth 40:99-116 
Koketsu K, Kikuchi M (2000) Propagation of seismic ground motion in the Kanto basin, Japan. Science 288(5469):1237-1239, doi:10.1126/science.288.5469.1237

Koketsu K, Miyake H (2008) A seismological overview of long-period ground motion. J Seismol 12:133-143, doi:10.1007/s10950-007-9080-0

Koketsu K, Hatayama K, Furumura T, Ikegami Y, Akiyama S (2005) Damaging long-period ground motions from the 2003 Mw 8.3 Tokachi-oki, Japan earthquake. Seismol Res Lett 76:67-73, doi:10.1785/gssrl.76.1.67

Koketsu K, Miyake H, Fujiwara H, Hashimoto T (2008) Progress towards a Japan integrated velocity structure model and long-period ground motion hazard map. In: Proceedings of the 14th World Conference on Earthquake Engineering, S10-038, Beijing, October 12-17, 2008

Koketsu K, Miyake H, Afnimar TY (2009) A proposal for a standard procedure of modeling 3-D velocity structures and its application to the Tokyo metropolitan area, Japan. Tectonophysics 472:290-300, doi:10.1016/j.tecto.2008.05.037

Koketsu K, Yokota Y, Nishimura N, Yagi Y, Miyazaki S, Satake K, Fujii Y, Miyake H, Sakai S, Yamanaka Y, Okada T (2011) A unified source model for the 2011 Tohoku earthquake. Earth Planet Sci Lett 310:480-487, doi:10.1016/j.epsl.2011.09.009

Maeda T, Furumura T (2013) FDM simulation of seismic waves, ocean acoustic waves and tsunamis based on tsunami-coupled equations of motion. Pure Appl Geophys 170:109-127, doi:10.1007/s00024-011-0430-z

Maeda T, Furumura T, Noguschi S, Takemura S, Sakai S, Shinohara M, Iwai K, Lee SJ (2013a) Seismic- and tsunami-wave propagation of the 2011 off the Pacific coast of Tohoku earthquake as inferred from the tsunami-coupled finitedifference simulation. Bull Seismol Soc Am 103:1456-1472, doi:10.1785/ 0120120118

Maeda T, Morikawa N, Iwaki A, Aoi S, Fujiwara H (2013b) Finite-difference simulation of long-period ground motion for the Nankai Trough megathrust earthquakes. J Disast Res 8(5):912-925

Maeda T, Furumura T, Obara K (2014) Scattering of teleseismic P-wave by the Japan Trench: a significant effect of reverberation in the seawater column. Earth Planet Sci Lett 397:101-110, doi:10.1016/j.epsl.2014.04.037

Matsuoka T, Shiraishi H (2002) Application of an exploration method using microtremor array observations for high resolution surveys of deep geological structures in the Kanto plains: estimation of 3-D S-wave velocity structure in the southern part of Saitama prefecture. Butsuri Tansa 55(2):127-143, in Japanese with English abstract

Ministry of Education, Sports, Culture, Science and Technology, Japan (MEXT) (2007) Deep seismic exploration. In: MEXT (ed) Annual report of special project for earthquake disaster mitigation in urban areas, I. Regional characterization of the crust in metropolitan areas for prediction of strong ground motion. MEXT, Tokyo, pp. 215-230

Miura H, Midorikawa S (2001) Effects of 3-D deep underground structure on characteristics of rather long-period ground motion: examination in and around Yokohama City. Zisin 54:381-395, in Japanese with English abstract

Miyake H, Koketsu K (2005) Long-period ground motions from a large offshore earthquake: the case of the 2004 off the Kii peninsula earthquake, Japan. Earth Planets Space 57:203-207

Moczo P, Robertsson OA, Einster $L$ (2007) The finite-difference time-domain method for modeling of seismic wave propagation. In: Wu R-S, Maupin V (eds), Advances in wave propagation in heterogeneous earth. Adv Geophys 48:421-516, doi:10.1016/S0065-2687(06)48008-0

Okada Y, Kasahara K, Hori S, Obara K, Sekiguchi S, Fujiwara H, Yamamoto A (2004) Recent progress of seismic observation networks in Japan-Hi-net, F-net, K-NET and KiK-net-. Earth Planets Space 56:xv-xxviii

Ravve I, Koren Z (2006) Exponential asymptotically bounded velocity model: part I-effective models and velocity transformations. Geophysics 71:T53-T65, doi:10.1190/1.2196033

Robertsson J, Blanch JO, Symes WW (1994) Viscoelastic finite-difference modeling. Geophysics 59:1444-1456, doi:10.1190/1.1443701

Senna S, Maeda T, Inagaki Y, Suzuki H, Matuyama H, Fujiwara H (2013) Modeling of the subsurface structure from the seismic bedrock to the ground surface for a broadband strong motion evaluation. J Disast Res 8(5):889-903

Shin T-C, Teng T-L (2001) An overview of the 1999 Chi-Chi, Taiwan, Earthquake. Bull Seismol Soc Am 91:895-913, doi:10.1785/0120000738

Shiomi K, Sato H, Ohtake M (1997) Broad-band power-law spectra of well-log data in Japan. Geophys J Int 130:57-64, doi:10.1111/j.1365-246X.1997.tb00987.x

Takemura S, Yoshimoto K (2014) Strong seismic wave scattering in the lowvelocity anomaly associated with subduction of oceanic plate. Geophys J Int 197:1016-1032, doi:10.1093/gji/ggu031

Wessel P, Smith WHF (1998) New improved version of generic mapping tools released. EOS, Trans Am Geophys Union 79(47):579, doi:10.1029/98EO00426
Yamamizu F (1996) Down-hole measurements of seismic wave velocities in deep soil deposits beneath the Tokyo metropolitan area. Rep Natl Res Inst Earth Sci Disaster Prev 56:1-32

Yamamizu F (2004) Seismic wave velocity structures in Kanto area as revealed by the crustal activity observation well VSP. Tech Note Natl Res Inst Earth Sci Disaster Prev 251:1-75, in Japanese with English abstract

Yamanaka H, Yamada N (2006) Estimation of 3D S-wave velocity model of the Kanto basin, Japan, using Rayleigh wave phase velocity. Bull Earthq Res Inst Univ Tokyo 81:295-301

Yamanaka H, Seo K, Samano T (1989) Effects of sedimentary layers on surfacewave propagation. Bull Seismol Soc Am 79:631-644

Yamanaka H, Komada N, Yamada N (2005) Estimation of 3D S-wave velocity model of the Kanto basin, Japan, for prediction of long-period ground motion. In: Proceedings of 2 nd international conference on urban earthquake engineering, Tokyo, 7-8 March 2005

Yamazaki K, Minamishima M, Kudo K (1992) Propagation characteristics of intermediate-period (1-10 seconds) surface waves in the Kanto Plain, Japan. J Phys Earth 40:117-136

Yoshimoto K, Takemura S (2014a) Surface wave excitation at northern edge of Kanto basin, Japan. Earth Planets Space 66:16, doi:10.1186/1880-5981-66-16

Yoshimoto K, Takemura S (2014b) A study on the predominant period of longperiod ground motions in the Kanto Basin, Japan. Earth Planets Space 66:100, doi:10.1186/1880-5981-66-100

\section{Submit your manuscript to a SpringerOpen ${ }^{\circ}$ journal and benefit from:}

- Convenient online submission

Rigorous peer review

- Immediate publication on acceptance

- Open access: articles freely available online

- High visibility within the field

- Retaining the copyright to your article

Submit your next manuscript at $>$ springeropen.com 